\title{
Eosinophilic esophagitis: an Italian experience
}

\author{
C. Vindigni ${ }^{1}$, V. Villanacci ${ }^{2}$, M. Marini ${ }^{3}$, B. J. Rocca ${ }^{4}$, G. Frosini ${ }^{3}$, E. Pedruzzi², N. Corazzi ${ }^{5}$, \\ G. Bassotti ${ }^{5}$ and P. Tosi ${ }^{4}$
}

${ }^{1}$ Division of Pathological Anatomy. AOUS. Siena, Italy. ${ }^{2}{ }^{\text {nd }}$ Department of Surgical Pathology. Spedali Civili of Brescia. Italy; ${ }^{3}$ Division of Gastroenterology and Digestive Endoscopy. AOUS, Siena, Italy. ${ }^{4}$ Division of Pathological Anatomy. Department of Human Pathology and Oncology. University of Siena. Italy. ${ }^{5}$ Gastroenterology and Hepatology Section. Department of Clinical and Experimental Medicine. University of Perugia. Italy

\begin{abstract}
Background: eosinophilic esophagitis is an esophageal disorder characterized by esophageal and/or upper gastrointestinal tract symptoms, and by dense esophageal eosinophilia associated with a normal gastric and duodenal mucosa. Prevalently reported in children, eosinophilic esophagitis has recently been reported with increased frequency also in adults.

Aims: the purpose of this study was to report our experience with eosinophilic esophagitis in Italy, since there are only very few series of such patients in our country.

Patients and methods: we retrospectively reviewed the histological data of consecutive patients with a diagnosis of esophagitis or reflux disease in the period September 2004-September 2008. Eosinophils were counted where they appeared most numerous in the biopsy, with a cutoff $>15$ eosinophils in more than one high-power field as diagnostic of eosinophilic esophagitis. $\mathrm{Pa}-$ tients were excluded if gastric or duodenal biopsies showed a prominent eosinophilic infiltrate.

Results: twenty two patients (14 adults, 8 children, age range 2-59 years) were identified according to the above criteria. The average eosinophil count was 86/ high-power field (range 31150 ), associated with other pathologic features (eosinophilic microabscesses eosinophil degranulation, basal zone hyperplasia, papillary elongation). The main clinical complaints were dysphagia, food impaction, and heartburn, and endoscopic findings consisted of mucosal thickening and inelasticity, longitudinal shearing, rings, and white specks, without difference between adults and children for both clinical and endoscopic variables.
\end{abstract}

Conclusions: eosinophilic esophagitis is not rare in Italy, and displays clinical, endoscopic, and pathologic features similar to those described in other countries.

Key words: Esophagitis. Eosinophils.

\footnotetext{
Received: 31-08-09.
}

Accepted: 07-10-09.

Correspondence: Gabrio Bassotti. Clinica di Gastroenterologia ed Epatologia. Ospedale Santa Maria della Misericordia. Piazzale Menghini, 1. 06156 San Sisto (Perugia), Italy. e-mail: gabassot@tin.it
Vindigni $C$, Villanacci V, Marini $M$, Rocca BJ, Frosini $G, P e-$ druzzi E, Corazzi N, Bassotti G, Tosi P. Eosinophilic esophagitis: an Italian experience. Rev Esp Enferm Dig 2010; 102: 15-19.

\section{INTRODUCTION}

Eosinophilic esophagitis (EE) is a primary disease of the esophagus characterized by esophageal and/or upper gastrointestinal tract symptoms and by dense esophageal eosinophilia associated with a normal gastric and duodenal mucosa $(1,2)$. EE may be considered an immune-mediated condition, probably caused by a disregulation with a mixed allergic response to foods and possibly other environmental antigens (3).

$\mathrm{EE}$ is more predominant in males, young adults and children, and is often associated with a personal and family history of allergic disease (4-7).

Recent studies suggest an increase in the prevalence of EE $(8,9)$, but it is unclear whether this is due to better awareness of the disease by gastroenterologists and pathologists, or to a truly rising incidence.

With respect to the clinical features of EE, some differences are noted between presenting symptoms in children and adults. In fact, reflux-like symptoms, nausea, vomiting, and abdominal pain are prevalent in children, whereas dysphagia and food impaction are more commonly found in adults (10-15). Differences in symptoms in EE affecting different ages could however be probably due to the capacity of patients at different ages to properly communicate symptoms.

At endoscopy, several mucosal abnormalities have been identified, including friability, white specks, whitish exudates, "crepe paper mucosa", narrow caliber esophagus, longitudinal furrows, and transient or fixed rings $(5,13,14,16-20)$. Some studies have also reported a nor- 
mal mucosa (5); however, over the last decade, as literature has developed, endoscopists are more focused on such possible endoscopic features.

For a definitive diagnosis it is important to obtain biopsies during endoscopy and to evaluate the exact degree of eosinophilic infiltration. It has been stressed that multiple biopsy specimens improve the diagnostic ability because of the heterogeneous distribution of eosinophilic infiltration. Gonsalves et al. (21) reported a sensitivity of $100 \%$ with 5 biopsy specimens. Biopsies should also be obtained from the stomach and duodenum to rule out eosinophilic gastroenteritis.

The interaction between EE and gastroesophageal reflux disease (GERD) is controversial. It has been postulated that GERD may contribute to EE by exposing the deep layers of the esophageal epithelium to antigens that ordinarily pass without penetrating the normal mucosa, or $\mathrm{EE}$ may contribute to GERD by increasing cellular permeability rendering the esophageal mucosa more susceptible to injury by refluxed gastric juice (22). EE and GERD may also coexist as differentiated entities in a single patient (23). Thus, it has been suggested that a proton-pump inhibitor (PPI) therapy should be attempted for patients suspected of having EE to exclude gastroesophageal reflux as a cause for the eosinophilic infiltrate (24).

We report a series of eosinophilic esophagitis from Italy, based on histological features and correlated with clinical and endoscopic findings.

\section{PATIENTS AND METHODS}

This was a retrospective study. In the period September 2004-September 2008 esophageal biopsy specimens from consecutive patients with a histological diagnosis of esophagitis or GERD (and in whom gastric and duodenal biopsies were also available) were retrieved from the archives of the Division of Pathological Anatomy, University of Siena, Italy, and reviewed by two pathologists (C.V. and V.V.). The diagnosis of EE included esophageal eosinophilic infiltrates and excluded gastroesophageal reflux in a clinically suitable context $(25,26)$.

Eosinophils were counted where they appeared most numerous in the biopsy. We considered a cutoff $>15$ eosinophils in more than one high-power field (HPF, $\mathrm{x} 400)$ as diagnostic of EE. Patients were excluded if gastric or duodenal biopsies showed a prominent eosinophilic infiltrate.

The highest density of intra-epithelial eosinophils (IEEs) for each patient was recorded as the number of IEEs per single HPF. In addition, the preferential distribution of IEEs (superficial, peripapillary or diffuse), eosinophilic microabscesses (considered as an aggregate of $>4$ eosinophils), eosinophil degranulation, basal zone hyperplasia ( $>20 \%$ of total epithelial height), papillary elongation ( $>60 \%$ of total epithelial height), epithelial edema, and fibrosis were evaluated.
For each patient we also obtained clinical information, including the primary complaint, allergy history, and endoscopic findings.

\section{Statistical analysis}

The statistical analysis was performed using the Systat 10.2 statistical software. The chi-squared test and the Kruskall-Wallis test were used to compare clinical, endoscopic and pathological findings between children and adults. Values of $\mathrm{p}<0.05$ were chosen for rejection of the null hypothesis.

\section{Ethical considerations}

Since this was a retrospective study, no individual patient identification was involved and no study-driven clinical intervention was performed; therefore no ethical approval was necessary.

\section{RESULTS}

In the period under observation 525 specimens from suspected GERD patients were analyzed. Of these, 22 (4\%) fulfilled the above criteria for EE. At least 4 samples, two from the middle esophagus and two about $2 \mathrm{~cm}$ above the esophago-gastric junction, were available for each patient. The clinico-pathological findings in our cases are reported in table I. All these patients had received high-dose proton pump inhibitors for at least two months, and none had shown symptom improvement. The patient group consisted of 15 men and 7 women (male-female

Table I. Clinico-pathological findings in EE patients

\begin{tabular}{lcccc}
\hline & \multicolumn{2}{c}{ Age $\leq 18$ years } & \multicolumn{2}{c}{ Age $>18$ years } \\
& $n$ & $\%$ & $n$ & $\%$ \\
\hline Number of patients & 8 & 36 & 14 & 64 \\
Mean age at diagnosis (range) & $12(2-18)$ & \multicolumn{2}{c}{38 (28-59) } \\
Sex (males) & 5 & 62 & 10 & 77 \\
History of allergic disease & 2 & 25 & 5 & 38 \\
Symptoms at presentation & & & & \\
$\quad$ Dysphagia & 6 & 75 & 7 & 54 \\
$\quad$ Food impaction & 3 & 37 & 3 & 23 \\
$\quad$ Heartburn & 4 & 50 & 5 & 38 \\
Endoscopic findings & & & & \\
$\quad$ Longitudinal shearing & 4 & 50 & 6 & 46 \\
$\quad$ Concentric rings & 1 & 12 & 5 & 38 \\
$\quad$ White specks & 2 & 25 & 2 & 15 \\
$\quad$ Thickening and inelasticity & 4 & 50 & 6 & 46 \\
$\quad$ Erosion & & - & 1 & 8 \\
$\quad$ Normality & 1 & 12 & - & - \\
Histopathological findings & & & & \\
$\quad$ Eosinophilic infiltration in biopsy (mean) & $75(30-140)$ & & $83(35-170)$ \\
\hline
\end{tabular}


ratio $2: 1) ; 14$ cases $(64 \%)$ were $>18$ years of age. The mean age of adults was 38 years (range 28-59), whereas that of children was 12 years (range 2-18). The prevalence of EE had a trend toward increasing from 2004 (two cases reported) to 2008 (11 cases).

The most common symptoms were dysphagia (64\%), food impaction (32\%), and heartburn (32\%), without difference between adults and children. Interestingly, these symptoms were present for 2-6 years before the diagnosis of EE. Associated allergic diseases (bronchial asthma) were present in two children and five adults (32\% of cases).

The most frequent endoscopic findings were mucosal thickening and inelasticity (54\%), longitudinal shearing (50\%), rings (27\%), and white specks (23\%) (Fig. 1). There was no significant difference in endoscopic findings between children and adults. Erosions were described in one adult case, and were associated with hiatus hernia. In another adult case the endoscopic findings were normal.

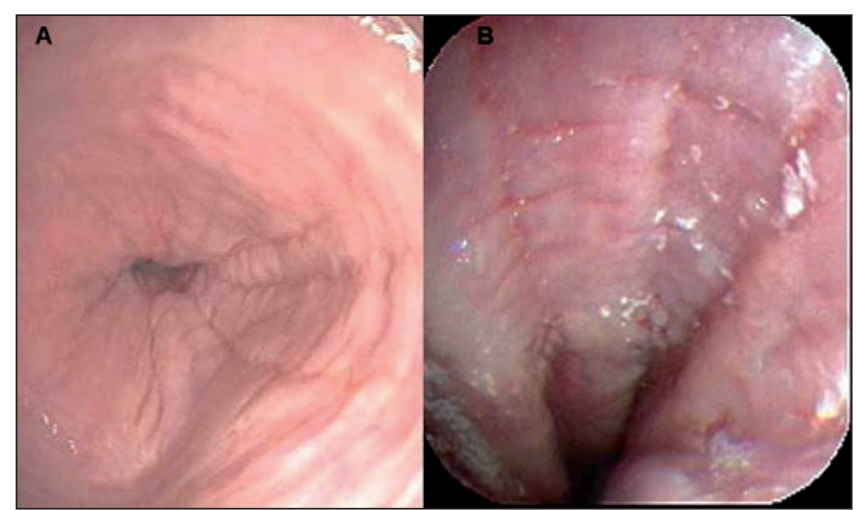

Fig. 1. Endoscopic findings in eosinophilic esophagitis. A. Mucosal rings. B. Longitudinal furrows and nodular mucosa.

Mean eosinophil count was 86 eosinophils/HPF (31150 eosinophils/hpf). Eosinophil distribution was predominantly superficial and peripapillary; eosinophilic microabscesses were present in all cases, mostly at the luminal edge of the epithelium (Fig. 2). Eosinophil degranulation was reported in 11 cases $(50 \%)$, and was correlated with the number of intraepithelial eosinophils. Basal zone hyperplasia, papilla elongation, intercellular edema, and lamina propria eosinophils were always present. A subepithelial lamina propria was present in four biopsy samples, with marked fibrosis of the lamina propria found in two cases. Eosinophil infiltration was present only in esophageal samples, and never in gastric or duodenal biopsies.

Follow-up data were available for six adult patients treated with oral prednisone for a month; after treatment, eosinophilic infiltrate and symptoms disappeared in four of them, with residual moderate eosinophilic infiltrate and sporadic dysphagia still present in the other two.

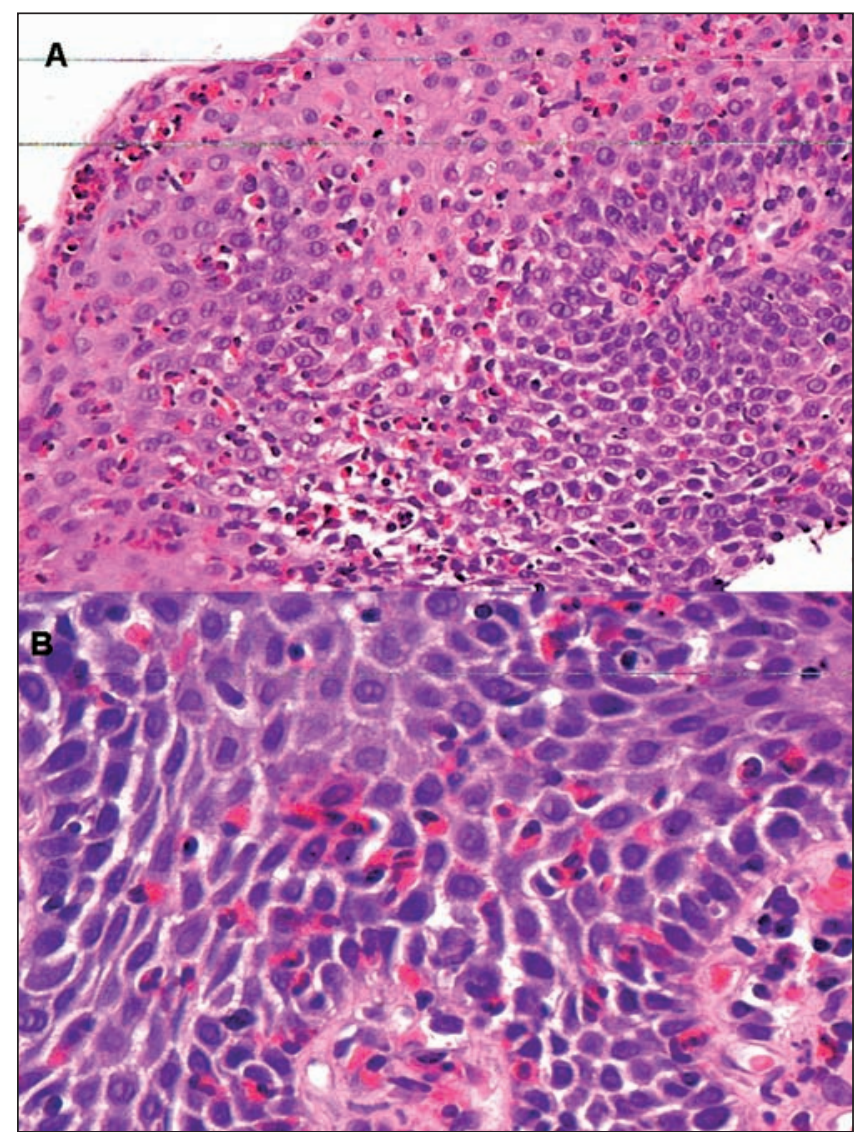

Fig. 2. A. Predominantly superficial distribution of eosinophils in EE. B. Eosinophilic microabscesses. H\&E, original magnification $\times 400$.

\section{DISCUSSION}

EE is considered an immune-mediated condition (16), probably caused by an immunological dysregulation in patients with personal susceptibility to allergic diseases (27). A family and personal history of atopy supports an allergic hypothesis. In this study we report a series of patients with EE, and this is one of the largest cohorts in our country, since most cases described in Italy were case reports (28-30).

As reported in other series from different countries (47 ), we have found a male predominance for this entity. It has been hypothesized that gender may confer a different risk to immune-related diseases (31). However, differences between both genders were not observed in an analysis of the gene expression profile in EE (32).

Although EE is well recognized in the pediatric population, it has been increasingly reported of late in adults $(6,7)$. The diagnosis is usually made in the $3^{\text {rd }}$ to $4^{\text {th }}$ decade, but symptoms are often present for a long period. In our adult patients the average age at diagnosis was 38 years. The most frequent symptoms were dysphagia and food impaction, without difference between adults and 
children. In our cases an associated allergic disease was reported in a low number of patients, probably because a specific reporting of allergy histories is often omitted from the clinical record.

Even in our cohort we found some endoscopic findings that should raise suspicion for EE, such as inelasticity and thickening, vertical furrowing, concentric rings, and whitish exudates.

The number of intraepithelial eosinophils in esophageal biopsy specimens is the main diagnostic criterion for EE. The highest number of eosinophils counted in one HPF is the method most commonly used, even though the number used is variable among studies. Some authors suggest the presence of $>20-25$ eosinophils in one HPF or $>15$ eosinophils in multiple HPFs $(1,6,22,33,34)$, in parallel with other developed countries all around the world.

Other common histopathologic features observed in EE were also present in our series; for instance, eosinophil degranulation was found in $50 \%$ of patients, and eosinophil microabscesses (mainly located at the luminal edge of the epithelium) in all of them. Moreover, we found the preferential superficial distribution of eosinophil infiltrates, basal zone hyperplasia and papillary lengthening in all subjects, whereas fibrosis of the lamina propria was found in two cases.

For a correct diagnosis it is important to have a high suspicion index and to obtain biopsies during endoscopy. The relationship between GERD and EE is not clear, and it must be kept in mind that these entities may sometimes co-exist (35). On the other hand, the recognition of EE and its differentiation from GERD are of clinical importance, since allergen elimination or anti-inflammatory therapy may be more effective than acid suppression $(36,37)$. Moreover, endoscopy with biopsy is the best method to monitor treatment response (38).

In conclusion, EE is increasingly recognized in our country, and displays clinical and pathological variables similar to those described in other countries. Thus, pediatricians, gastroenterologists, and endoscopists should be sensitized towards this not uncommon entity.

\section{REFERENCES}

1. Furuta GT, Liacouras CA, Collins MH, Gupta SK, Justinich C, Putnam PE, et al.; First International Gastrointestinal Eosinophil Research Symposium (FIGERS) Subcommittees. Eosinophilic esophagitis in children and adults: a systematic review and consensus recommendations for diagnosis and treatment. Gastroenterology 2007; 133: 1342-63.

2. Noel RJ, Putnam PE, Rothenberg ME. Eosinophilic esophagitis. N Engl J Med 2004; 351: 940-1.

3. Markowitz JE, Liacouras CA. Ten years of eosinophilic oesophagitis: small steps or giant leaps? Dig Liver Dis 2006; 38: 251-3.

4. Croese J, Fairley SK, Masson JW, Chong AK, Whitaker DA, Kanowski PA, et al. Clinical and endoscopic features of eosinophilic esophagitis in adults. Gastrointest Endosc 2003, 58: 516-22.

5. Liacouras CA, Spergel JM, Ruchelli E, Verma R, Mascarenhas M,
Semeao E, et al. Eosinophilic esophagitis: a 10-year experience in 381 children. Clin Gastroenterol Hepatol 2005, 3: 1198-206.

6. Parfitt JR, Gregor JC, Suskin NG, Jawa HA, Driman DK. Eosinophilic esophagitis in adults: distinguishing features from gastroesophageal reflux disease: a study of 41 patients. Mod Pathol 2006; 19: 90-6.

7. Sgouros SN, Bergele C, Mantides A. Eosinophilic esophagitis in adults: what is the clinical significance? Endoscopy 2006; 38: 51520.

8. Straumann A, Simon HU. Eosinophilic esophagitis: escalating epidemiology? J Allergy Clin Immunol 2005; 115: 418-9.

9. Ronkainen J, Talley NJ, Aro P, Storskrubb T, Johansson SE, Lind T, et al. Prevalence of oesophageal eosinophils and eosinophilic oesophagitis in adults: the population-based Kalixanda study. Gut 2007; 56: 615-20.

10. Kelly KJ, Lazenby AJ, Rowe PC, Yardley JH, Perman JA, Sampson HA. Eosinophilic esophagitis attributed to gastroesophageal reflux: improvement with an amino acid-based formula. Gastroenterology 1995; 109: 1503-12.

11. Fox VL, Nurko S, Teitelbaum JE, Badizadegan K, Furuta GT. Highresolution EUS in children with eosinophilic "allergic" esophagitis. Gastrointest Endosc 2003; 57: 30-6.

12. Straumann A, Spichtin HP, Grize L, Bucher KA, Beglinger C, Simon HU. Natural history of primary eosinophilic esophagitis: a follow-up of 30 adult patients for up to 11.5 years. Gastroenterology 2003; 125 : $1660-9$.

13. Desai TK, Stecevic V, Chang CH, Goldstein NS, Badizadegan K, Furuta GT. Association of eosinophilic inflammation with esophageal food impaction in adults. Gastrointest Endosc 2005; 61: 795-801.

14. Kerlin P, Jones D, Remedios M, Campbell C. Prevalence of eosinophilic esophagitis in adults with food bolus obstruction of the esophagus. J Clin Gastroenterol 2007; 41: 356-61.

15. Debrosse CW, Rothenberg ME. Allergy and eosinophil-associated gastrointestinal disorders (EGID). Curr Opin Immunol 2008; 20: 703-8.

16. Lim JR, Gupta SK, Croffie JM, Pfefferkorn MD, Molleston JP, Corkins MR, et al. White specks in the esophageal mucosa: an endoscopic manifestation of non-reflux eosinophilic esophagitis in children. Gastrointest Endosc 2004; 59: 835-8.

17. Potter JW, Saeian K, Staff D, Massey BT, Komorowski RA, Shaker R, et al. Eosinophilic esophagitis in adults: an emerging problem with unique esophageal features. Gastrointest Endosc 2004; 59: 355-61.

18. Zimmerman SL, Levine MS, Rubesin SE, Mitre MC, Furth EE, Laufer I, et al. Idiopathic eosinophilic esophagitis in adults: the ringed esophagus. Radiology 2005; 236: 159-65.

19. Remedios M, Campbell C, Jones DM, Kerlin P. Eosinophilic esophagitis in adults: clinical, endoscopic, histologic findings, and response to treatment with fluticasone propionate. Gastrointest Endosc 2006; 63: 3-12.

20. Fox VL. Eosinophilic esophagitis: endoscopic findings. Gastrointest Endosc Clin N Am 2008; 18: 45-57.

21. Gonsalves N, Policarpio-Nicolas M, Zhang Q, Rao MS, Hirano I. Histopathologic variability and endoscopic correlates in adults with eosinophilic esophagitis. Gastrointest Endosc 2006; 64: 313-9.

22. Spechler SJ, Genta RM, Souza RF. Thoughts on the complex relationship between gastroesophageal reflux disease and eosinophilic esophagitis. Am J Gastroenterol 2007; 102: 1301-6.

23. Molina-Infante J, Ferrando-Lamana L, Mateos-Rodríguez JM, PérezGallardo B, Prieto-Bermejo AB. Overlap of reflux and eosinophilic esophagitis in two patients requiring different therapies: a review of the literature. World J Gastroenterol 2008; 14: 1463-6.

24. Ngo P, Furuta GT, Antonioli DA, Fox VL. Eosinophils in the esophagus-peptic or allergic eosinophilic esophagitis? Case series of three patients with esophageal eosinophilia. Am J Gastroenterol 2006; 101: 1666-70.

25. Martín Martín L, Santander Vaquero C, Sánchez Prudencio S, Cantero Perona J,Gisbert JP, Moreno-Otero R. Eosinophilic esophagitis in the adult -clinical, endoscopic, $\mathrm{pH}$-metric, and manometric findings. Rev Esp Enferm Dig 2008; 100: 476-80.

26. Lucendo Villarín AJ. Eosinophilic esophagitis: clinical manifestations, diagnosis, and treatment. Rev Esp Enferm Dig 2009; 101: 49-59. 
27. Villalta D, Baragiotta AM. Eosinophilic esophagitis: from the case report to the evidence. Eur Ann Allergy Clin Immunol 2008; 40: 5360.

28. Cantù P, Velio P, Prada A, Penagini R. Ringed oesophagus and idiopathic eosinophilic oesophagitis in adults: an association in two cases. Dig Liver Dis 2005; 37: 129-34.

29. Liguori G, Cortale M, Cimino F, Sozzi M. Circumferential mucosal dissection and esophageal perforation in a patient with eosinophilic esophagitis. World J Gastroenterol 2008; 14: 803-4.

30. Francalanci P, De Angelis P, Minnei F, Diomedi Camassei F, Torroni F, Dall'Oglio L, et al. Eosinophilic esophagitis and Barrett's esophagus: an occasional association or an overlap disease? Esophageal 'double trouble' in two children. Digestion 2008; 77: 169.

31. Bartlett JA, Schleifer SJ, Demetrikopoulos MK, Delaney BR, Shiflett SC, Keller SE. Immune function in healthy adolescents. Clin Diagn Lab Immunol 1998; 5: 105-13.

32. Blanchard C, Wang N, Stringer KF, Mishra A, Fulkerson PC, Abonia
JP, et al. Eotaxin-3 and a uniquely conserved gene-expression profile in eosinophilic esophagitis. J Clin Invest 2006; 116: 536-47.

33. Steiner SJ, Gupta SK, Croffie JM, Fitzgerald JF. Correlation between number of eosinophils and reflux index on same day esophageal biopsy and 24 hour esophageal $\mathrm{pH}$ monitoring. Am J Gastroenterol 2004; 99: 801-5.

34. Antonioli DA, Furuta GT. Allergic eosinophilic esophagitis: a primer for pathologists. Semin Diagn Pathol 2005; 22: 266-72.

35. Ramakrishnan R, Chong H. Eosinophilic oesophagitis in adults. Histopathology 2008; 52: 897-900.

36. Armisén M, Vidal C, López-Rosés L, Rodríguez V, Bartolomé B. Eosinophilic esophagitis due to allergy to sheep and goat milk proteins. Rev Esp Enferm Dig 2008; 100: 53-6.

37. Bohm M, Richter JE. Treatment of eosinophilic esophagitis: overview, current limitations, and future direction. Am J Gastroenterol 2008; 103: 2635-44.

38. Fass R, Gasiorowska A. Refractory GERD: what is it? Curr Gastroenterol Rep 2008; 10: 252-7. 